Research Article

\title{
Modified Nishihara Rheological Model considering the Effect of Thermal-Mechanical Coupling and Its Experimental Verification
}

\author{
Xingang Wang, ${ }^{1,2,3}$ Qiangbing Huang, ${ }^{1}$ Baoqin Lian $\mathbb{D}^{1},{ }^{1}$ Nina Liu, ${ }^{1}$ and Jun Zhang ${ }^{2}$ \\ ${ }^{1}$ Key Laboratory of Western China's Mineral Resource and Geological Engineering of Ministry of Education, \\ School of Geology Engineering and Surveying, Chang'an University, Xi'an 710054, China \\ ${ }^{2}$ Key Laboratory of Mine Geological Hazards Mechanism and Control, Shaanxi Institute of Geo-Environment Monitoring, \\ Xian 710054, China \\ ${ }^{3}$ State Key Laboratory of Continental Dynamics, Department of Geology, Northwest University, Xi'an, Shaanxi 710069, China \\ Correspondence should be addressed to Baoqin Lian; qin20054184@126.com
}

Received 21 May 2018; Accepted 15 November 2018; Published 5 December 2018

Academic Editor: Fernando Lusquiños

Copyright (C) 2018 Xingang Wang et al. This is an open access article distributed under the Creative Commons Attribution License, which permits unrestricted use, distribution, and reproduction in any medium, provided the original work is properly cited.

\begin{abstract}
The effect of temperature and pressure, which play important roles in the mechanical properties of rocks during deep energy exploitation, has not been sufficiently studied in the previous rock creep models. In order to investigate thermal effect in creep models, a modified Nishihara rheological model, taking into account the coupled effect of thermal damage and stress, was proposed by combining the theoretical formula for thermal damage of rocks with the modified Nishihara model. The improved model introduces a nonlinear viscous dashpot, which can accurately describe the accelerated rheological phase of rocks. To verify the proposed model, a triaxial rheological experiment was conducted on sandstone subjected to thermal damage $\left(600^{\circ} \mathrm{C}\right)$. In addition, the stress-strain curves within whole creep process of the rheological experiment were analyzed. Furthermore, the theoretical curves of the modified Nishihara rheological model were compared with the experimental results. Results showed that the theoretical curves relatively agree well with the experimental data, suggesting that the proposed new model is more preferred to describing the rheological curve of sandstone subjected to thermal damage at different rheological stages, in particular, it is capable of depicting the accelerated rheological stage of the sandstone, providing a good ability to describe the creep behavior of rocks under thermal-mechanical coupling.
\end{abstract}

\section{Introduction}

The exploitation of the deep earth resources is necessary due to the worldwide exhaustion of shallow resources. During deep energy exploitation, deep rocks are in a certain geological environment, in which temperature and pressure significantly affect the mechanical properties of rocks $[1,2]$. Therefore, a good understand of the deformation and strength characteristics of rocks under different temperature and pressure conditions would be significant [3].

There have been a number of studies with an aim to understand the thermal effect on the mechanical properties of rocks. For example, Tian et al. [4] studied the mechanical properties change of sandstone subject to high-temperature heating and derived the relationship between the physical parameters and temperature. Brotóns et al. [5] investigated the effect of temperature ranging from $105^{\circ} \mathrm{C}$ to $600^{\circ} \mathrm{C}$ on the uniaxial compressive strength, modulus of elasticity, and Poisson's ratio as well as other mechanical properties of calcarenite. Otto and Kempka [6] concluded that the change in permeability associated with the thermomechanical properties of rocks is negligible during underground coal gasification. Zhu and Arson [7] studied thermomechanical crack opening and closure in rocks and proposed a thermomechanical damage model without considering time 
effect. Wisetsaen et al. [8] probed into the effect of temperature and loading rate on the tensile strength of rock salt. Sun et al. [9] reported the change of thermal conductivity coefficient, thermal diffusion coefficient, and thermal capacity of sandstone after high-temperature treatment and found that four stages in the variation of thermal parameters with temperature: from room temperature to $200^{\circ} \mathrm{C}$, $200^{\circ} \mathrm{C}-400^{\circ} \mathrm{C}, 400^{\circ} \mathrm{C}-600^{\circ} \mathrm{C}$, and above $600^{\circ} \mathrm{C}$. Yang et al. [10] carried out tests on granite after treatment at temperature ranging from $25^{\circ} \mathrm{C}$ to $900^{\circ} \mathrm{C}$ and concluded the variation in coefficient of thermal expansion and microcrack with change of temperature.

However, investigating into the conventional mechanical behavior of the rock cannot accurately simulate the field conditions, in which rock mass always undergoes rheological behavior that is closely related to the long-term stability and safety of engineering rock mass [11-13]. Furthermore, thermal damage will intensify the rheological effect of rocks, which directly affects the long-term safety of permanent works [14-16].

There have been many studies which documented the rheological behavior of rock mass under the thermal effect without proposing the model. For example, Kinoshita and Inada [17] performed uniaxial creep tests on granite at the temperature ranging from $20^{\circ} \mathrm{C}$ to $100^{\circ} \mathrm{C}$ and asserted that temperature accelerates the creep failure of rocks. Dwivedi et al. [18] investigated the change of thermomechanical properties of Indian granite at high temperatures from $30^{\circ} \mathrm{C}$ to $160^{\circ} \mathrm{C}$ and found that internal friction decrease with increase of temperature. Chen et al. [19] and Chen et al. [20] studied the time-dependent behavior of the Beishan granite at different stress levels and temperature and found that the temperature that is higher than $90^{\circ} \mathrm{C}$ and stress effect on the critical state to failure is found to be more pronounced. Ye et al. [21] concluded that the thermal effect on creep failure time was significant.

Unfortunately, studies on the rheological constitutive relation of rocks under the coupled effect of thermal damage and stress with introducing a suitable model are scare. Recently, Yang et al. [3] conducted a multiloading triaxial creep test on red sandstone through treatment at different temperatures in range of $25^{\circ} \mathrm{C}$ to $1000^{\circ} \mathrm{C}$ and proposed a creep damage model which considers the damage variable from the aspect of dissipation energy, without taking the thermal effect on the rock damage model into account. Moreover, the model parameters do not have specific physical meaning. However, an incorrect model can yield misleading results. A deep investigation of the rheological constitutive model is thus necessary which requires further in-depth research. In this study, a coupled thermal damage-stress constitutive model based on the modified Nishihara rheological model was proposed, which introduces damage variable related with thermal effect and well reflect the rheological behavior of sandstone subjected to thermal damage and stress change. Subsequently, the improved model was verified with the experiments data. Finally, the new model was compared with Nishihara and Burgers model.

\section{Rheological Constitutive Analysis of Thermal Damage-Stress Coupling}

2.1. Analysis of Thermal Damage of Rocks. The development of rock damage with the strain is a continuous process. Rocks are divided into several microunits containing defects, and the following assumptions are made for microunits $[22,23]$ :

(i) The representative microunits behave the linear elastic

(ii) The failure agrees with the von Mises yield criterion

(iii) The strength follows the Weibull statistical law $W(m, \lambda)$, i.e.,

$$
\varphi(\varepsilon)=\frac{m}{\lambda} \varepsilon^{m-1} \exp \left[-\left(\frac{\varepsilon}{\lambda}\right)^{m}\right]
$$

where $\varphi(\varepsilon)$ is the strength probability of microunits with corresponding microstrain; $m$ is the morphological parameters of Weibull statistics; $\lambda$ is the mean microstrain of all microunits; $\varepsilon$ is the microstrain of microunits.

The correlation between the damage variable $D$ and the strain $\varepsilon$ is expressed as

$$
\frac{d D}{d \varepsilon}=\varphi(\varepsilon)
$$

No damage is assumed under initial conditions, i.e., $\varepsilon=$ $0, D=0$, which gives

$$
D=\int_{0}^{\varepsilon} \varphi(\varepsilon) d \varepsilon=1-\exp \left[-\left(\frac{\varepsilon}{\lambda}\right)^{m}\right] .
$$

The microunits follow the von Mises yield criterion, thus,

$$
\left(\sigma_{1}-\sigma_{2}\right)^{2}+\left(\sigma_{2}-\sigma_{3}\right)^{2}+\left(\sigma_{3}-\sigma_{1}\right)^{2}=2 \sigma_{0}^{2}
$$

where $\sigma_{0}$ is the deviatoric stress, with $\sigma_{2}=\sigma_{3}$ under confining pressure in the triaxial test, the above equation can be simplified to

$$
\left|\sigma_{1}-\sigma_{3}\right|=\sigma_{0}
$$

Then, according to the generalized Hooker theorem, the following equation can be obtained:

$$
\varepsilon=\frac{\varepsilon_{z}-(1-2 \mu) \sigma_{3}}{E},
$$

where $\varepsilon_{z}$ is the maximum axial strain, $\mu$ is Poisson's ratio, and $E$ is the elastic modulus. Damage variable equation can be derived combining equations (6) and (3), which is written as

$$
D=1-\exp \left[-\left(\frac{\varepsilon_{z} E-(1-2 \mu) \sigma_{3}}{\lambda E}\right)^{m}\right] .
$$

As a matter of fact, rock damage is associated not only with axial pressure, but also with thermal effect. Therefore, a temperature function must be introduced into equation (7).

The relationship between the fractal dimension $m$ and the temperature $T$ of rocks reported by Chen et al. [24] is introduced in this study, which is expressed as 


$$
m=A T^{2}+B T+C,
$$

where $A, B$, and $C$ are parameters obtained from the conventional triaxial compression test and $T$ is the temperature.

From equations (7) and (8), the damage variable equation for rocks under the coupled effect of temperature and stress is obtained, which is written as

$$
D=1-\exp \left[-\left(\frac{\varepsilon_{z} E-(1-2 \mu) \sigma_{3}}{\lambda E}\right)^{A T^{2}+B T+C}\right] .
$$

\subsection{Modified Nishihara Model and Its Constitutive Equation.} The Nishihara model which is widely used in the research on mechanical rheological properties of rocks, consisting of a Bingham body and a Kelvin (Voigt) body connected in series [25], is shown in Figure 1.

Rheological equation of the Nishihara model:

$$
\begin{cases}\varepsilon(t)=\frac{\sigma_{0}}{E_{1}}+\frac{\sigma_{0}}{E_{2}}\left(1-e^{-\left(E_{2} / \eta_{1}\right) t}\right) & \text { if } \sigma_{0}<\sigma_{s}, \\ \varepsilon(t)=\frac{\sigma_{0}}{E_{1}}+\frac{\sigma_{0}-\sigma_{s}}{\eta_{2}} t+\frac{\sigma_{0}}{E_{2}}\left(1-e^{-\left(E_{2} / \eta_{1}\right) t}\right) & \text { if } \sigma_{0} \geq \sigma_{s},\end{cases}
$$

where $E_{1}$ is the instantaneous elastic modulus, $E_{2}$ is the viscoelastic modulus, $\eta_{1}, \eta_{1}$, and $\eta_{2}$ are the viscosity coefficients, $\sigma_{s}$ is the yield stress of rock materials, and the yield strength is adopted by using the method reported by Meng et al. [26], and $\varepsilon$ is the total strain.

The Nishihara model can well describe the initial rheological stage and the stable rheological stage in the rheological process of rocks, but it is difficult to depict the accelerated rheological stage of rocks. Therefore, a nonlinear viscous dashpot was introduced to describe the deformation of rocks at the accelerated rheological stage. When the overall strain of rocks is less than the value of strain (this value is defined as $\varepsilon_{a}$ ) corresponding to the moment when rocks enter the accelerated rheological stage, this nonlinear viscous dashpot will not work. Conversely, when the overall strain of the model is greater than $\varepsilon_{a}$, the dashpot will be triggered immediately. $\eta_{3}$ is the viscosity coefficient of the nonlinear viscous dashpot. Connecting the nonlinear viscous dashpot to the classical Nishihara model in series, the modified Nishihara model is shown in Figure 2.

The constitutive model of this nonlinear viscous dashpot is defined as

$$
\begin{cases}\sigma_{0}=\eta_{3} \ddot{\varepsilon}_{4} & \text { if } \varepsilon \geq \varepsilon_{\mathrm{a}} \\ \varepsilon_{3}=0 & \text { if } \varepsilon \leq \varepsilon_{\mathrm{a}} .\end{cases}
$$

When the total strain of rocks is $\varepsilon<\varepsilon_{a}$, this model is degenerated to the classical Nishihara model. When $\varepsilon \geq \varepsilon_{a}$, the rocks enter the accelerated rheological stage and the nonlinear viscous dashpot is triggered. Furthermore, the deviator stress has exceeded its yield stress $\sigma_{\mathrm{s}}$ at this moment, and the total strain of the modified Nishihara model is

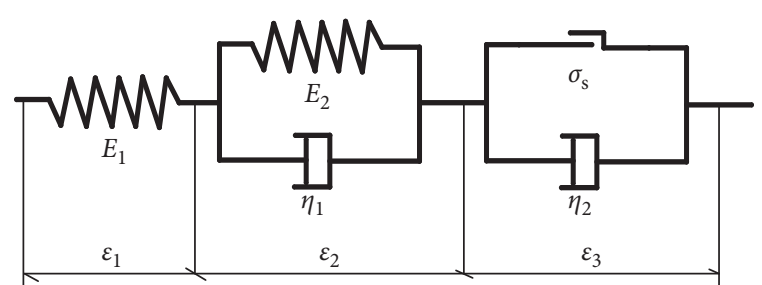

Figure 1: Nishihara model.

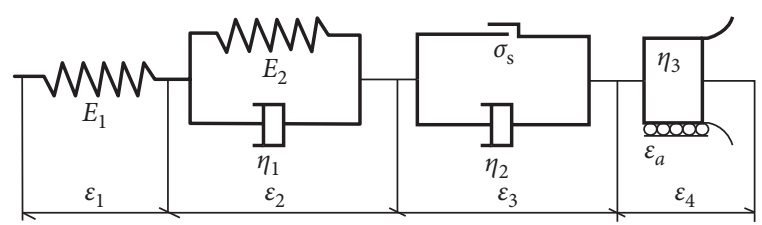

Figure 2: The modified Nishihara model.

$$
\varepsilon=\varepsilon_{1}+\varepsilon_{2}+\varepsilon_{3}+\varepsilon_{4},
$$

where $\varepsilon_{1}, \varepsilon_{2}, \varepsilon_{3}$, and $\varepsilon_{4}$ are the strain corresponding to each rheological body shown in Figure 2. Applying the Laplace transform of equation (10)-(13) is obtained [27]:

$$
\left\{\begin{array}{l}
\widehat{\varepsilon}_{1}(s)+\widehat{\varepsilon}_{2}(s)+\widehat{\varepsilon}_{3}(s)=\frac{\sigma_{0}}{E_{1} s}+\frac{\sigma_{0}}{\left(E_{2}+\eta_{1} s\right) s}+\frac{\sigma_{0}-\sigma_{s}}{\eta_{2} s^{2}}, \\
\widehat{\varepsilon}_{4}(s)=\frac{\sigma_{0}}{\eta_{3} s^{s^{2}}} \\
\widehat{\varepsilon}(s)=\widehat{\varepsilon}_{1}(s)+\widehat{\varepsilon}_{2}(s)+\widehat{\varepsilon}_{3}(s)+\widehat{\varepsilon}_{4}(s),
\end{array}\right.
$$

where $\widehat{\varepsilon}$ is the Laplace transform of $\varepsilon$ and $s$ is the complex variable of Laplace transform. From equation (13), the following equation can be further obtained:

$$
\widehat{\varepsilon}(s)=\frac{\sigma_{0}}{E_{1} s}+\frac{\sigma_{0}}{\left(E_{2}+\eta_{1} s\right) s}+\frac{\sigma_{0}-\sigma_{s}}{\eta_{2} s^{2}}+\frac{\sigma_{0}}{\eta_{3} s^{3}} .
$$

The inverse Laplace transform of equation (14) gives the rheological equation of the modified Nishihara model at the accelerated rheological stage, which is written as

$$
\varepsilon(t)=\frac{\sigma_{0}}{E_{1}}+\frac{\sigma_{0}-\sigma_{s}}{\eta_{2}} t+\frac{\sigma_{0}}{E_{2}}\left(1-e^{-\left(E_{2} / \eta_{1}\right) t}\right)+\frac{\sigma_{0}}{\eta_{3}} t^{\prime},
$$

where $t^{\prime}=t-t_{a}$, where $t_{a}$ is the time corresponding to the accelerated rheological stage of rocks.

\subsection{Rheological Equation of the Modified Nishihara Model} under the Coupled Effect of Thermal Damage and Stress. The theoretical formula for thermal damage of rocks is combined into the modified Nishihara model to propose the rheological constitutive equation of the modified Nishihara model under the coupled effect of thermal damage and stress. The new rheological constitutive equation is divided into three phases:

(i) $\sigma_{0}<\sigma_{s}, D=0$ at the decelerated rheological stage and the stable rheological stage, in which damage has not occurred, 
(ii) $\sigma_{0} \geq \sigma_{\mathrm{s}}, D=0$ when the total stress of rocks is greater than the yield stress but the total strain of rocks is $\varepsilon<\varepsilon_{a}$,

(iii) When the total stress of rocks is greater than the yield stress and the total strain of rocks is $\varepsilon \geq \varepsilon_{a}$, the rocks enter the accelerated rheological stage. At this moment, $\sigma_{0} \geq \sigma_{s}$, and $D$ is calculated according to equation (9).

Therefore, the rheological constitutive equation of the modified Nishihara model under the coupled effect of thermal damage and stress is obtained, which is expressed as

$$
\varepsilon(t)= \begin{cases}\frac{\sigma_{0}}{E_{1}}+\frac{\sigma_{0}}{E_{2}}\left(1-e^{-\left(E_{2} / \eta_{1}\right) t}\right) & \text { if } \sigma_{0}<\sigma_{s} \\ \frac{\sigma_{0}}{E_{1}}+\frac{\sigma_{0}}{E_{2}}\left(1-e^{-\left(E_{2} / \eta_{1}\right) t}\right)+\frac{\sigma_{0}-\sigma_{s}}{\eta_{2}} t & \text { if } \sigma_{0} \geq \sigma_{s}, \varepsilon<\varepsilon_{a} \\ \frac{\sigma_{0}}{E_{1}}+\frac{\sigma_{0}}{E_{2}}\left(1-e^{-\left(E_{2} / \eta_{1}\right) t}\right)+\frac{\left(\sigma_{0}-\sigma_{s}\right)(1-D)}{\eta_{2}} \cdot t+\frac{\sigma}{\eta_{3}} t^{\prime} & \text { if } \sigma_{0} \geq \sigma_{s}, \varepsilon \geq \varepsilon_{a} .\end{cases}
$$

As the stress of triaxial creep test is $\sigma_{2}=\sigma_{3}$, according to equation (16), the creep equation of the modified
Nishihara rheological model in the triaxial test can be derived as

$$
\varepsilon(t)= \begin{cases}\frac{\sigma_{0}+2 \sigma_{3}}{9 K}+\frac{\sigma_{0}}{3 G_{1}}+\frac{\sigma_{0}}{3 G_{2}}\left(1-e^{-\left(G_{2} / \eta_{1}\right) t}\right) & \text { if } \sigma_{0}<\sigma_{\mathrm{s}}, \\ \frac{\sigma_{0}+2 \sigma_{3}}{9 K}+\frac{\sigma_{0}}{3 G_{1}}+\frac{\sigma_{0}}{3 G_{2}}\left(1-e^{-\left(G_{2} / \eta_{1}\right) t}\right)+\frac{\sigma_{0}-\sigma_{s}}{2 \eta_{2}} t & \text { if } \sigma_{0} \geq \sigma_{\mathrm{s}}, \varepsilon<\varepsilon_{a}, \\ \frac{\sigma_{0}+2 \sigma_{3}}{9 K}+\frac{\sigma_{0}}{3 G_{1}}+\frac{\sigma_{0}}{3 G_{2}}\left(1-e^{-\left(G_{2} / \eta_{1}\right) t}\right)+\frac{\left(\sigma_{0}-\sigma_{s}\right)(1-D)}{2 \eta_{2}} \cdot t+\frac{\sigma_{0}}{2 \eta_{3}} t^{\prime} & \text { if } \sigma_{0} \geq \sigma_{s}, \varepsilon \geq \varepsilon_{a} .\end{cases}
$$

where $K$ is the bulk modulus of the specimen; $G_{1}$ and $G_{2}$ are the shear moduli corresponding to $E_{1}$ and $E_{2}$ in the threedimensional stress state [25].

\section{Laboratory Test}

3.1. Test Procedure. The temperature-stress coupling triaxial rheometer for rocks was used in the laboratory rheological test [28]. The device is mainly employed to perform rheological tests on rock materials under coupling of stress, temperature, seepage, etc (Figure 3). The rheological tests were carried out by complying with procedures as follows:

(1) Prepare standard rock samples $50 \mathrm{~mm}$ in diameter and $100 \mathrm{~mm}$ in height for rheological and other routine tests. To prevent the difference in microcrack among rock samples which would affect test results, the elastic modulus test was performed on standard rock samples. And then, the samples with similar wave velocity from the elastic modulus tests were selected for triaxial creep tests.

(2) Rock blocks were heated in a furnace at the high temperature of $600^{\circ} \mathrm{C}$, and then cooled down naturally to the room temperature. Additionally, to rationally design the loading level for the relevant rheological test, one group of sandstone blocks was selected to conduct conventional triaxial compression test. As the rheological test is time-consuming, one sandstone block was chosen to validate the proposed rheological constitutive model.

(3) Selected rock samples were wrapped with a thermal shrinkable rubber sleeve, and then a couple of rigid blocks with the diameter approximately equal to that of the rock sample were placed at each ends. Subsequently, rock samples were placed in the triaxial rheological chamber. And then, the axial displacement sensor and lateral displacement sensor were adjusted and finally the triaxial pressure cylinder was gently put down.

(4) Based on the results of the triaxial compression test of sandstone subjected to thermal damage (the conventional triaxial compressive strength is $220 \mathrm{MPa}$ with the confining pressure of $3 \mathrm{MPa}$ ), the multiloading method employed in this study is shown in Table 1. At each level of loading, the loading duration is kept for at least $72 \mathrm{~h}$ and the deformation increment is less than $0.001 \mathrm{~mm}$ within 


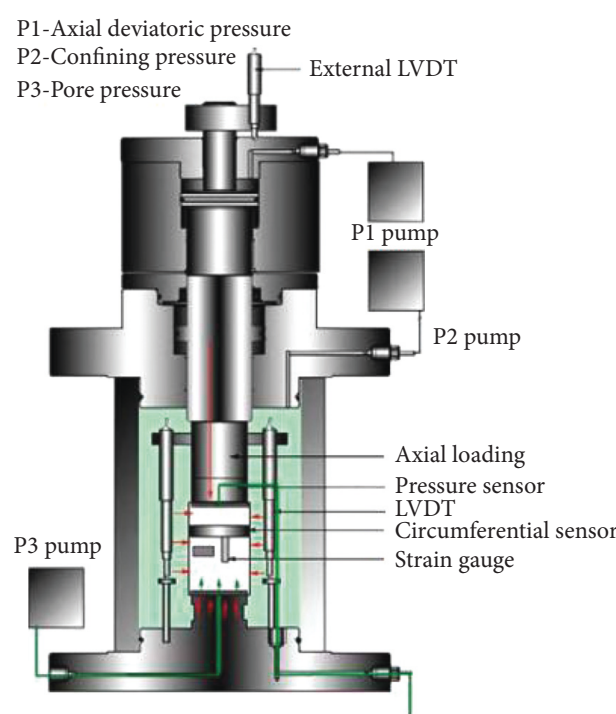

FIgURE 3: Temperature-stress coupling triaxial rheometer equipment (after Zhang et al. [29]).

TABLE 1: Sandstone rheological test load level.

Axial load (MPa)

First level Second level Third level Fourth level Fifth level

\begin{tabular}{lllll}
\hline 35 & 65 & 100 & 135 & 175 \\
\hline
\end{tabular}

$24 \mathrm{~h}$, and it can be considered that the creep generated by applying of this level of load has basically become stable, and then the next level of load can be applied. The loading level is increased until sample failure occurs. Data are collected automatically during test, and the stress-strain curve is plotted at the same time.

(5) Stop the test and take out the sample, and then record and describe the details.

(6) Put the device in the original position and store the sample.

3.2. Test Results and Analysis. After the laboratory triaxial rheological test was finished, data were processed to obtain the axial, hoop, and volumetric strain-time curves, as shown in Figure 4.

In Figure 4, the sandstone subjected to thermal damage undergoes the instantaneous elastic deformation stage, decelerated rheological stage, stable rheological stage, and accelerated rheological stage in the rheological test. Under low stress, the sandstone only experiences the first three stages. However, four stages will take place in sequence only when the axial stress approaches or reaches the critical failure value. At the moment, each level of axial stress is applied, instantaneous elastic deformation of the sandstone occurs, suggesting that the sandstone has the elastic characteristic, and instantaneous elastic deformation changes with the different applied axial stress level. Obviously, the instantaneous elastic deformation of rock samples in axial and hoop directions basically decreases as the axial stress

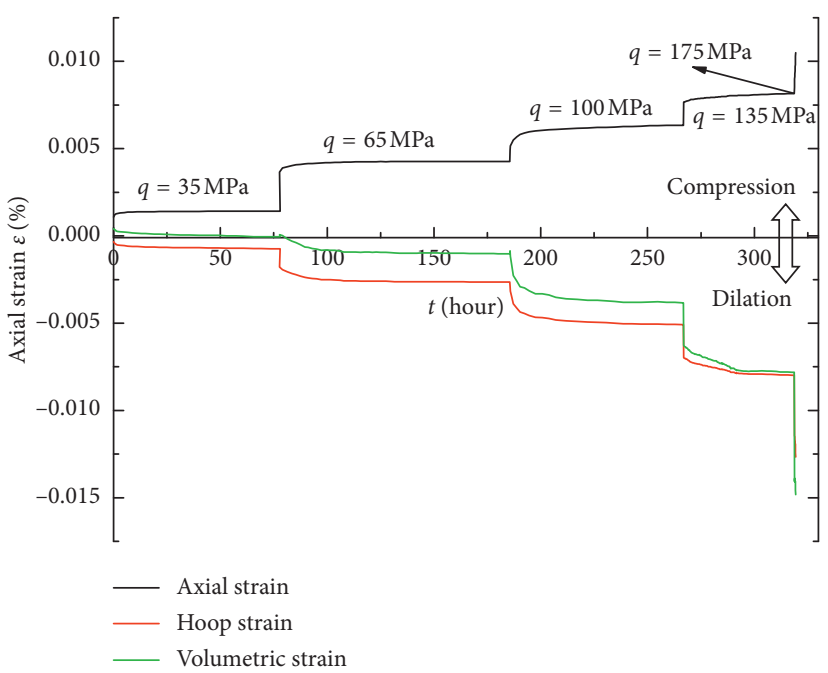

FIgURE 4: The strain-time map of sandstone subjected to thermal damage $\left(\sigma_{3}=3 \mathrm{MPa}, T=600^{\circ} \mathrm{C}\right)$.

increases. The axial, hoop, and volumetric strains of the sandstone under each level of load are shown in Table 2. Under low stress level, the sandstone enters the decelerated rheological stage from the instantaneous elastic deformation stage, and the deformation gradually increases over time, while the deformation rate decreases over time. After a period of time, the deformation remains constant within a period of span. Under high stress, the sandstone enters the stable rheological stage after the instantaneous elastic deformation stage and the decelerated rheological stage. Under this condition, the deformation rate is greater than zero, and the strain continuously accumulates over time. When the strain accumulation exceeds a certain critical value, the sandstone will rapidly enter the accelerated rheological stage, and finally be subjected to rheological failure.

According to Figure 4, the axial, hoop, and volumetric strain curves are not quite smooth, exhibiting slight fluctuation and abrupt change in local segments of the strain curves. The reason is that inhomogeneous damage, existing in the internal structure of the sandstone in the rheological process, results in microweakening and cracking of the sandstone. Under the long-term continuous action of constant axial stress, areas with microdefects inside rock samples are gradually damaged. With accumulation over a long time, areas with relatively low strength in rock materials show inhomogeneous deformation and failure in microareas because they cannot bear the rheological damage caused by the effect of long-term accumulation of microdefects, which further results in irregular fluctuation and abrupt change of rock deformation.

\section{Validation of the Modified Nishihara Rheological Model}

To validate the rheological equation of the modified Nishihara model under the coupled effect of thermal damage and stress, firstly, the elastic modulus $E$ and Poisson's ratio $\mu$ of rocks were determined through the uniaxial compression 
TABle 2: The sandstone's strain values.

\begin{tabular}{lcccc}
\hline $\begin{array}{l}\text { Axial } \\
\text { stress/MPa }\end{array}$ & $\begin{array}{c}\text { Confining } \\
\text { pressure/MPa }\end{array}$ & $\varepsilon_{1}$ & $\varepsilon_{3}$ & $\varepsilon_{\mathrm{v}}$ \\
\hline 35 & 3 & 1420 & -734 & -47.2 \\
65 & 3 & 2850 & -1916 & -982.8 \\
100 & 3 & 2070 & -2440 & -2810 \\
135 & 3 & 1870 & -2890 & -3970 \\
175 & 3 & 2270 & -4680 & -7020 \\
Cumulative strain $/ 10^{-6}$ & 10480 & -12660 & -14830 \\
\hline
\end{tabular}

$\varepsilon_{1}, \varepsilon_{3}$, and $\varepsilon_{\mathrm{v}}$ in the table represent axial strain, hoop strain, and volumetric strain, respectively; hoop strain is negative at outward expansion.

test. Then the values of $m$ and $\lambda$ were calculated according to the data of routine triaxial test under different temperatures. Finally, the parameter values of $A, B$, and $C$ were calculated according to equations (8). The modified Nishihara rheological model fitting parameters, listed in Table 3, can be obtained by fitting the rheological experiments curve of axial strain in Figure 4 on the basis of the equations (8) and (17). In addition, the fitting results and experimental results were compared in Figure 5.

Figure 5 shows that the rheological equation of the modified Nishihara model under the coupled effect of thermal damage and stress established in this study are relatively consistent with the test results, which can well reflect the rheological process of sandstone subjected to thermal damage. It demonstrates the rationality and validity of the proposed rheological constitutive equation considering thermal damage.

\section{Discussion}

5.1. Long-Term Strength. Long-term strength, serving as an important mechanical index for assessing the long-term stability of rock and soil in engineering, is closely related to the safety in engineering construction and the stability in later operation $[30,31]$. Up to now, widely used methods for determining the long-term strength of rocks include isochronous stress-strain curve method, steady-state creep rate method, etc [32].

Based on the experimental data in Figure 5 and combined with the Boltzmann superposition principle [33], the isochronous curve of rocks shown in Figure 6 is obtained. By the isochronous stress-strain curve method, the long-term strength of sandstone after thermal damage at the temperature of $600^{\circ} \mathrm{C}$ is determined in the range of 120 and $140 \mathrm{MPa}$. As can be seen from Figure 6, with the isochronous curve method, the judgment about the turning point is strongly affected by individual visual observation, resulting in large errors. As reported by Cong and $\mathrm{Hu}$ [34], a certain value range of long-term strength can thus be obtained by individual observation and judgment. As for the steady-state creep rate method, the determination of the critical values for sudden change of steady-state creep rate and non-steadystate creep rate is relatively subjective, and large errors also exist due to individual judgment [32].

To solve the problem mentioned above, Liu and $\mathrm{Xu}$ [35] introduced a method named intersection method of steady creep rate based on the steady-state rate method. With this method, the stress value corresponding to the intersection point between the fitted curves of steady-state axial strain rate and steady-state volumetric strain rate under different levels of deviatoric stress is defined as the long-term strength of rocks. According to this method (as shown in Figure 7), the long-term strength of sandstone employed in this study, after thermal damage at the temperature of $600^{\circ} \mathrm{C}$, is $126 \mathrm{MPa}$.

5.2. Comparison of Creep Models. The experimental data shown in Figure 8 were fitted using the Burgers [36] and Nishihara models [37] and compared with the modified Nishihara rheological model. It is obvious in Figure 8 that the proposed model is in better agreement with the experimental data than the results estimated by the other traditional models.

The new model cannot reflect the initial creep stage and the steady-state creep stage of thermal-mechanical coupling effect of rocks. Particularly, this model is connected with a nonlinear viscous dashpot in series; therefore, it is capable of describing the accelerated creep stage of rocks. However, there are still some deficiencies in the proposed model. For example, only rheological curves of sandstone at the temperature of $600^{\circ} \mathrm{C}$ are used for verification in present study. Rheological curves under different temperature conditions and different lithological characters should be considered to verify the proposed model in our future work.

\section{Conclusion}

The triaxial rheological test was performed on sandstone subjected to thermal damage, and the rheological constitutive relation under the coupled effect of thermal damage and stress was investigated. Main conclusions of this study are drawn as follows:

(i) The Nishihara model was modified by connecting a nonlinear viscous dashpot in series. After combining the theoretical formula for thermal damage of rocks into the modified Nishihara model, the rheological constitutive equation of the modified Nishihara model under the effect of thermalmechanical coupling was proposed.

(ii) The sandstone subjected to thermal damage undergoes the instantaneous elastic deformation stage, decelerated rheological stage, stable rheological stage, and accelerated rheological stage in the rheological test. Under low stress, the sandstone only experiences the first three stages, while four stages will take place in sequence only when the axial stress approaches or reaches the critical failure value. Moreover, the axial, hoop, and volumetric strain curves are not quite smooth, and local segments of the strain curves exhibit slight fluctuation and abrupt change caused by the inhomogeneous damage existing in the internal structure of the sandstone. 
TABle 3: Model fitting parameters $\left(\sigma_{3}=3 \mathrm{MPa}, T=600^{\circ} \mathrm{C}\right)$.

\begin{tabular}{|c|c|c|c|c|c|c|}
\hline$\sigma_{0} / \mathrm{MPa}$ & $G_{1} /(\mathrm{GPa})$ & $G_{2} /(\mathrm{GPa})$ & $\eta_{1} /(\mathrm{GPa} \cdot \min )$ & $\eta_{2} /(\mathrm{GPa} \cdot \min )$ & $\eta_{3} /(\mathrm{GPa} \cdot \min )$ & $R^{2}$ \\
\hline 35 & 9.02 & 36.88 & 56.65 & N/A & $\mathrm{N} / \mathrm{A}$ & 0.99 \\
\hline 65 & 5.35 & 3.92 & 7.89 & $\mathrm{~N} / \mathrm{A}$ & N/A & 0.98 \\
\hline 100 & 5.54 & 17.60 & 24.05 & N/A & N/A & 0.95 \\
\hline 135 & 5.79 & 30.85 & 6.86 & 5.01 & N/A & 0.98 \\
\hline 175 & 5.88 & 155.93 & 26.49 & 21.15 & N/A & 0.98 \\
\hline 175 (accelerated stage) & 5.88 & 155.93 & 26.49 & 43.78 & 5369.8 & 0.99 \\
\hline
\end{tabular}

$R^{2}$ is the correlation coefficient, $\mathrm{N} / \mathrm{A}=$ not available.

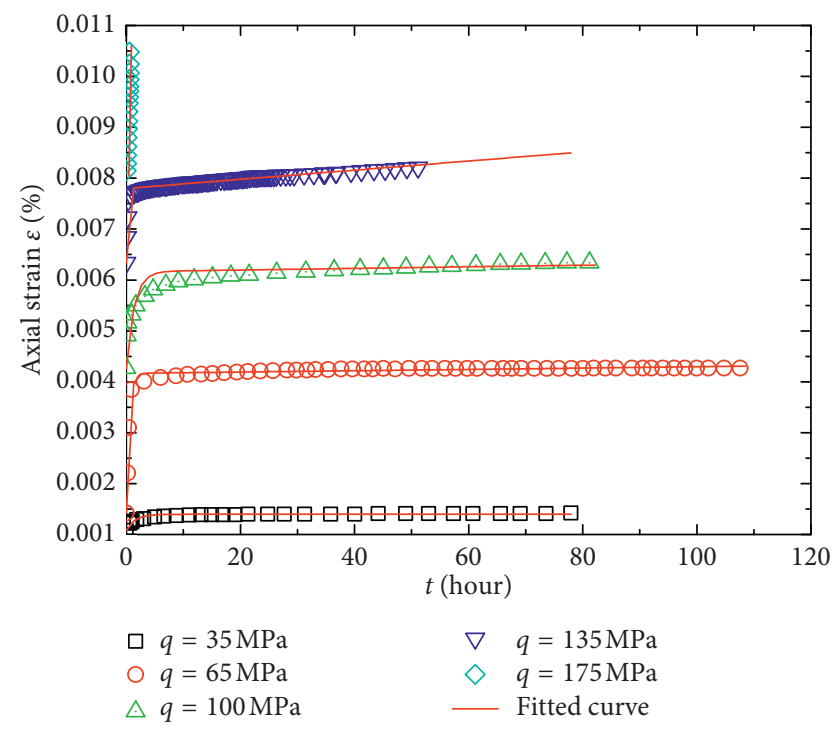

Figure 5: The rheological experiments curve and the fitting results $\left(\sigma_{3}=3 \mathrm{MPa}, T=600^{\circ} \mathrm{C}\right)$.

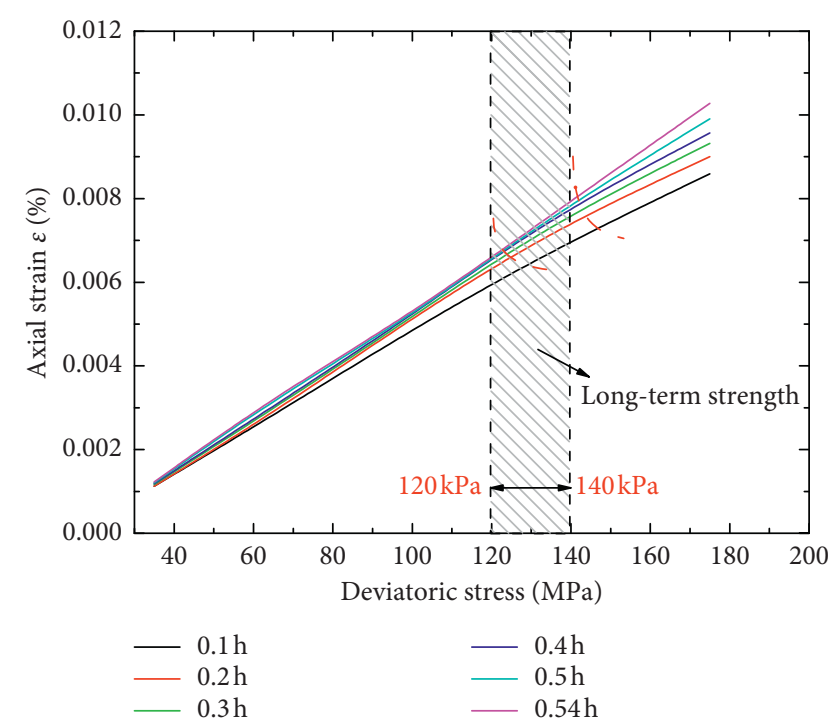

Figure 6: Isochronous curves of sample $\left(\sigma_{3}=3 \mathrm{MPa}, T=600^{\circ} \mathrm{C}\right)$.

(iii) Validation of the proposed rheological constitutive equation shows that this model is capable of describing the rheological process of sandstone subjected to thermal damage at different rheological stages, suggesting that the proposed rheological

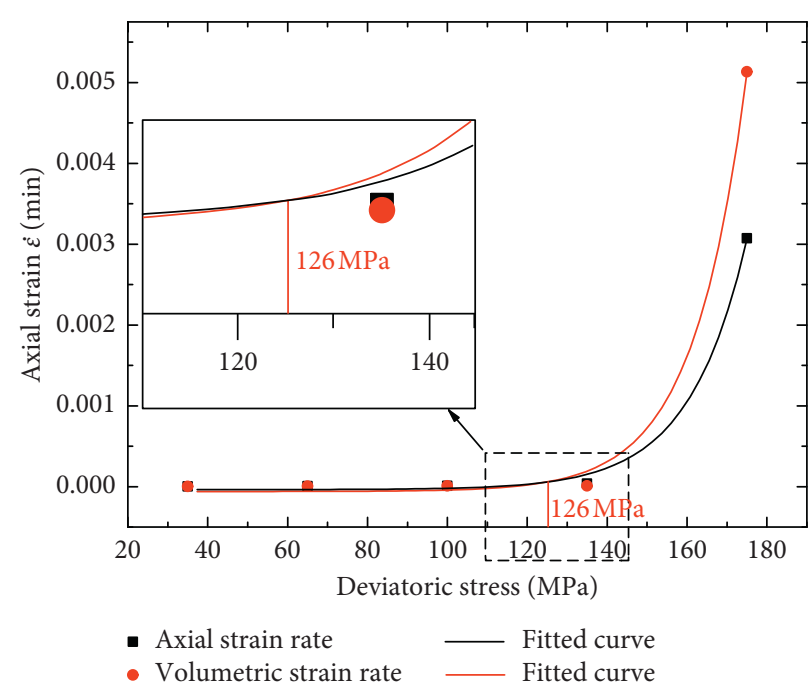

FIgURE 7: Relationship between axial strain rate and deviatoric stress $\left(\sigma_{3}=3 \mathrm{MPa}, T=600^{\circ} \mathrm{C}\right)$.

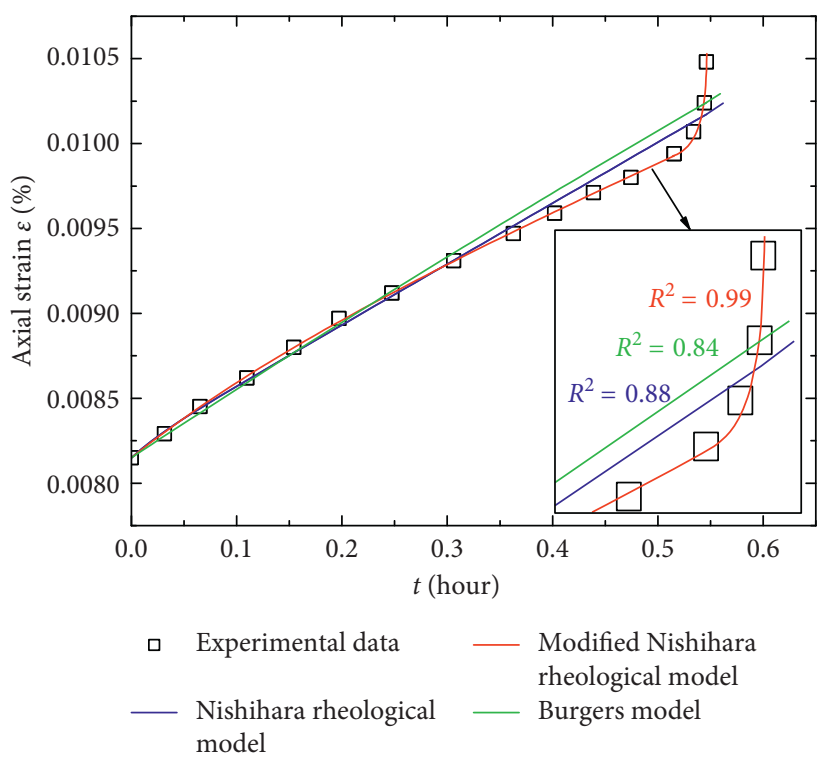

Figure 8: Experimental data and theoretical cuve $\left(\sigma_{3}=3 \mathrm{MPa}, \sigma_{0}\right.$ $=175 \mathrm{MPa}, T=600^{\circ} \mathrm{C}$ ).

constitutive equation considering thermal damage is rational and valid.

(iv) Limited by experimental conditions, the author has only verified the sandstone subjected to thermal 
damage at the temperature of $600^{\circ} \mathrm{C}$. Further research will focus on experimental verification of different lithological characterization at different temperatures, as well as the microcosmic laws before and after failure in rheological test.

\section{Data Availability}

The data used to support the findings of this study are available from the corresponding author upon request.

\section{Conflicts of Interest}

The authors declare that they have no conflicts of interest.

\section{Acknowledgments}

The research is supported by three funds, namely, (1) the Fundamental Research Funds for the Central Universities (no. 310826171108), (2) National Natural Science Foundation of key projects (no. 41790443), and (3) the Open Fund Project of Key Laboratory of Mine Geological Hazards Mechanism and Control (no. KF2017-03).

\section{References}

[1] M. Belmokhtar, P. Delage, S. Ghabezloo, and N. Conil, "Thermal volume changes and creep in the callovo-oxfordian claystone," Rock Mechanics and Rock Engineering, vol. 50, no. 9, pp. 2297-2309, 2017.

[2] W. Li, Y. Han, T. Wang, and J. Ma, "DEM micromechanical modeling and laboratory experiment on creep behavior of salt rock," Journal of Natural Gas Science and Engineering, vol. 46, pp. 38-46, 2017.

[3] S.-Q. Yang, B. Hu, P. Ranjith, and P. Xu, "Multi-step loading creep behavior of red sandstone after thermal treatments and a creep damage model," Energies, vol. 11, no. 1, p. 212, 2018.

[4] H. Tian, T. Kempka, S. Yu, and M. Ziegler, "Mechanical properties of sandstones exposed to high temperature," Rock Mechanics and Rock Engineering, vol. 49, no. 1, pp. 321-327, 2015.

[5] V. Brotóns, R. Tomás, S. Ivorra, and J. C. Alarcón, “Temperature influence on the physical and mechanical properties of a porous rock: san Julian's calcarenite," Engineering Geology, vol. 167, pp. 117-127, 2013.

[6] C. Otto and T. Kempka, "Thermo-mechanical simulations of rock behavior in underground coal gasification show negligible impact of temperature-dependent parameters on permeability changes," Energies, vol. 8, no. 6, pp. 5800-5827, 2015.

[7] C. Zhu and C. Arson, "A thermo-mechanical damage model for rock stiffness during anisotropic crack opening and closure," Acta Geotechnica, vol. 9, no. 5, pp. 847-867, 2013.

[8] S. Wisetsaen, C. Walsri, and K. Fuenkajorn, "Effects of loading rate and temperature on tensile strength and deformation of rock salt," International Journal of Rock Mechanics and Mining Sciences, vol. 73, pp. 10-14, 2015.

[9] Q. Sun, C. Lü, L. Cao, W. Li, J. Geng, and W. Zhang, "Thermal properties of sandstone after treatment at high temperature," International Journal of Rock Mechanics and Mining Sciences, vol. 85, pp. 60-66, 2016.

[10] S.-Q. Yang, W.-L. Tian, and Y.-H. Huang, "Failure mechanical behavior of pre-holed granite specimens after elevated temperature treatment by particle flow code," Geothermics, vol. 72, pp. 124-137, 2018.

[11] X. Wang, L. Huang, C. Yan, and B. Lian, "HKCV rheological constitutive model of mudstone under dry and saturated conditions," Advances in Civil Engineering, vol. 2018, Article ID 1049802, 10 pages, 2018.

[12] Y.-X. Wang, P. Cao, Y.-H. Huang, R. Chen, and J.-T. Li, "Nonlinear damage and failure behavior of brittle rock subjected to impact loading," International Journal of Nonlinear Sciences and Numerical Simulation, vol. 13, no. 1, p. 61, 2012.

[13] Y. Zhao, Y. Wang, W. Wang, W. Wan, and J. Tang, "Modeling of non-linear rheological behavior of hard rock using triaxial rheological experiment," International Journal of Rock Mechanics and Mining Sciences, vol. 93, pp. 66-75, 2017.

[14] C. Inserra, S. Biwa, and Y. Chen, "Nonlinear ultrasonic characterization of thermally damaged westerly granite," Japanese Journal of Applied Physics, vol. 48, no. 7, article 07GD03, 2009.

[15] L. L. Ngueyep Mambou, J. Ndop, and J. M. B. Ndjaka, "Theoretical investigations of mechanical properties of sandstone rock specimen at high temperatures," Journal of Mining Science, vol. 50, no. 1, pp. 69-80, 2014.

[16] G. Wu, Y. Wang, G. Swift, and J. Chen, "Laboratory investigation of the effects of temperature on the mechanical properties of sandstone," Geotechnical and Geological Engineering, vol. 31, no. 2, pp. 809-816, 2013.

[17] N. Kinoshita and Y. Inada, "Effects of high temperature on strength, deformation, thermal properties and creep of rocks," Journal of Society of Materials Science, vol. 55, no. 5, pp. 489-494, 2006.

[18] R. D. Dwivedi, R. K. Goel, V. V. R. Prasad, and A. Sinha, "Thermo-mechanical properties of Indian and other granites," International Journal of Rock Mechanics and Mining Sciences, vol. 45, no. 3, pp. 303-315, 2008.

[19] L. Chen, C. P. Wang, J. F. Liu, Y. Li, J. Liu, and J. Wang, "Effects of temperature and stress on the time-dependent behavior of Beishan granite," International Journal of Rock Mechanics and Mining Sciences, vol. 93, pp. 316-323, 2017.

[20] L. Chen, C. P. Wang, J. F. Liu et al., "A damage-mechanismbased creep model considering temperature effect in granite," Mechanics Research Communications, vol. 56, pp. 76-82, 2014.

[21] G.-1. Ye, T. Nishimura, and F. Zhang, "Experimental study on shear and creep behaviour of green tuff at high temperatures," International Journal of Rock Mechanics and Mining Sciences, vol. 79, pp. 19-28, 2015.

[22] L. Kachanov, "Crack and damage growth in creep-a combined approach," International Journal of Fracture, vol. 16, no. 4, pp. R179-R181, 1980.

[23] X. Wang, B. Hu, H. Tang, X. Hu, J. Wang, and L. Huang, "A constitutive model of granite shear creep under moisture," Journal of Earth Science, vol. 27, no. 4, pp. 677-685, 2016.

[24] J. Chen, C. Yang, and X. Gao, "Study on the coupled damage of temperature and mechanics for salt rock," Chinese Journal of Rock Mechanics and Engineering, vol. 24, pp. 1986-1991, 2005.

[25] X. Wang, Y. Yin, J. Wang, B. Lian, H. Qiu, and T. Gu, "A nonstationary parameter model for the sandstone creep tests," Landslides, vol. 15, pp. 1377-1389, 2018.

[26] Q. B. Meng, M. W. Zhang, L. J. Han, H. Pu, and Y. L. Chen, "Acoustic emission characteristics of red sandstone specimens under uniaxial cyclic loading and unloading compression," Rock Mechanics and Rock Engineering, vol. 51, no. 4, pp. 969-988, 2017. 
[27] H. Tang, D. Wang, R. Huang, X. Pei, and W. Chen, "A new rock creep model based on variable-order fractional derivatives and continuum damage mechanics," Bulletin of Engineering Geology and the Environment, vol. 77, no. 1, pp. 375-383, 2018.

[28] W.-y. Xu, R.-b. Wang, W. Wang, Z.-1. Zhang, J.-c. Zhang, and W.-y. Wang, "Creep properties and permeability evolution in triaxial rheological tests of hard rock in dam foundation," Journal of Central South University, vol. 19, no. 1, pp. 252-261, 2012.

[29] Y. Zhang, J. F. Shao, W. Y. Xu, Y. Jia, and H. B. Zhao, "Creep behaviour and permeability evolution of cataclastic sandstone in triaxial rheological tests," European Journal of Environmental and Civil Engineering, vol. 19, no. 4, pp. 496-519, 2014.

[30] N. A. Chandler, "Quantifying long-term strength and rock damage properties from plots of shear strain versus volume strain," International Journal of Rock Mechanics and Mining Sciences, vol. 59, pp. 105-110, 2013.

[31] Y. Zhang, J. Shao, W. Xu, and Y. Jia, "Time-dependent behavior of cataclastic rocks in a multi-loading triaxial creep test," Rock Mechanics and Rock Engineering, vol. 49, no. 9, pp. 3793-3803, 2016.

[32] Y.-j. Xie, Q. Fu, G.-c. Long, K.-r. Zheng, and H. Song, “Creep properties of cement and asphalt mortar," Construction and Building Materials, vol. 70, pp. 9-16, 2014.

[33] H. Sone and M. D. Zoback, "Time-dependent deformation of shale gas reservoir rocks and its long-term effect on the in situ state of stress," International Journal of Rock Mechanics and Mining Sciences, vol. 69, pp. 120-132, 2014.

[34] L. Cong and X. Hu, "Triaxial rheological property of sandstone under low confining pressure," Engineering Geology, vol. 231, pp. 45-55, 2017.

[35] L. Liu and W. Xu, "Experimental researches on long-term strength of granite gneiss," Advances in Materials Science and Engineering, vol. 2015, Article ID 325162, 9 pages, 2015.

[36] F. Bozzano, S. Martino, A. Montagna, and A. Prestininzi, "Back analysis of a rock landslide to infer rheological parameters," Engineering Geology, vol. 131-132, pp. 45-56, 2012.

[37] S. W. Hao, B. J. Zhang, J. F. Tian, and D. Elsworth, "Predicting time-to-failure in rock extrapolated from secondary creep," Journal of Geophysical Research: Solid Earth, vol. 119, no. 3, pp. 1942-1953, 2014. 


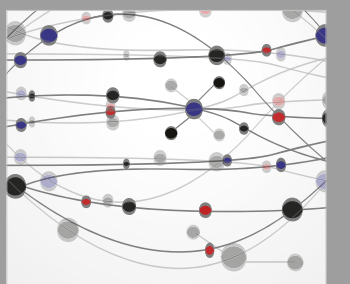

The Scientific World Journal
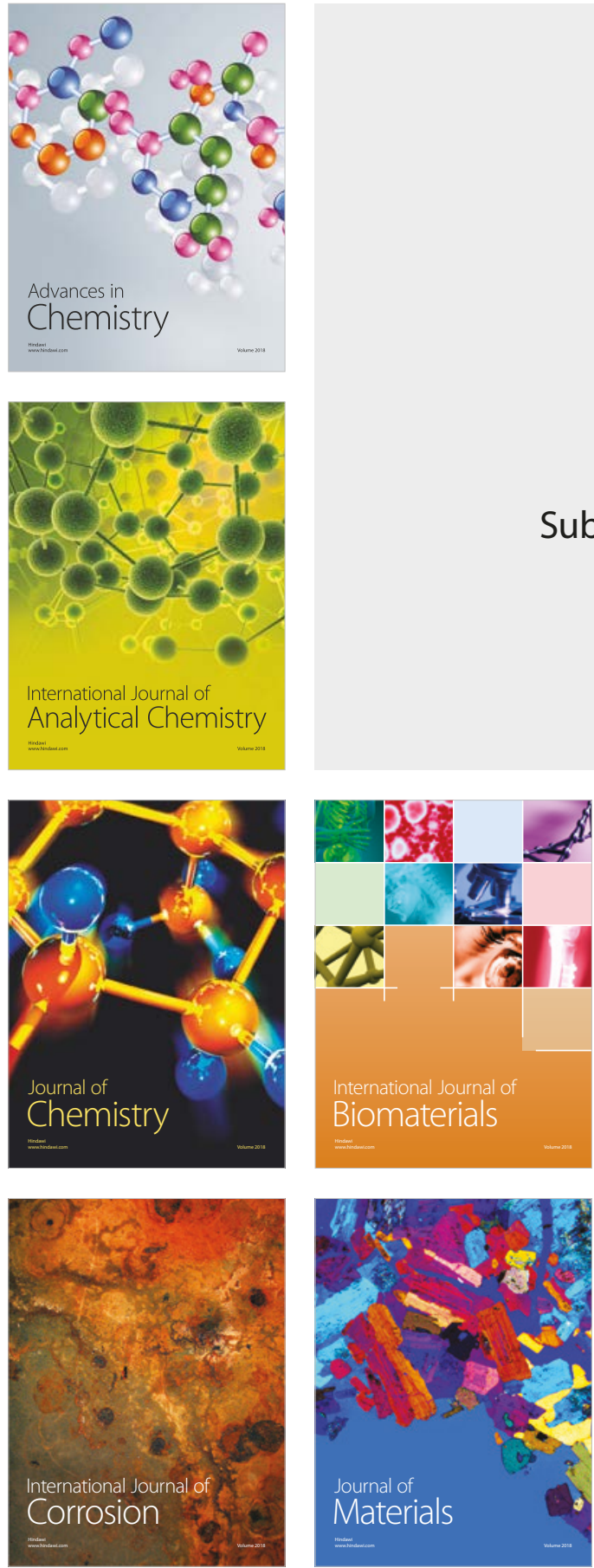

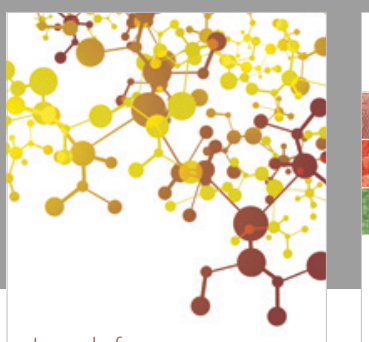

Journal of

Applied Chemistry
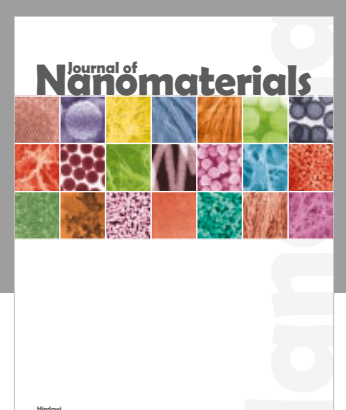

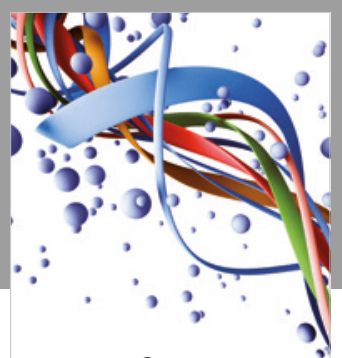

Scientifica

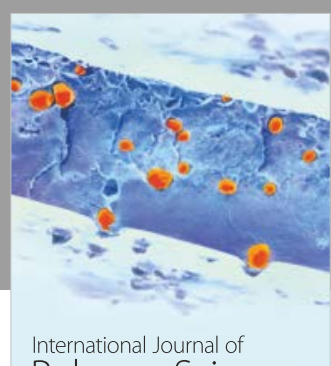

Polymer Science

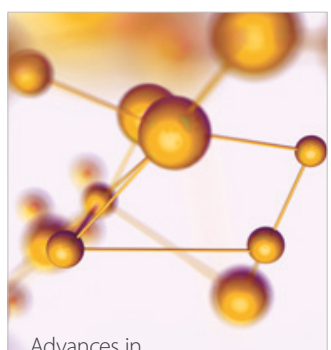

Physical Chemistry
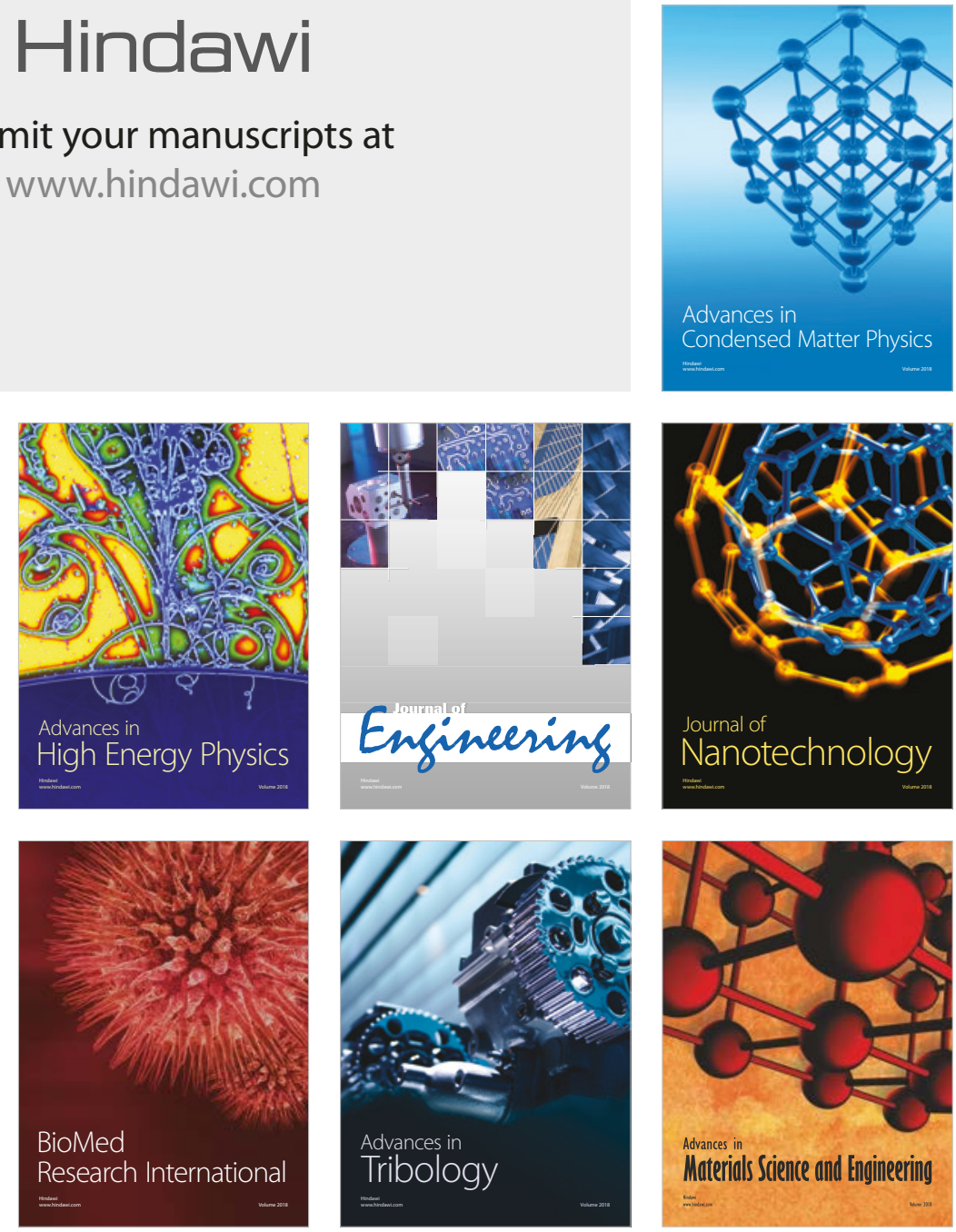